\title{
O PIBIDcomo terceiro espaço: elementos para formação de professores de ciências na profissão
}

\author{
The PIBID as a third space: elements for science teachers training \\ on the profession
}

\author{
Paula Vanessa Bervian ${ }^{1}$ \\ Eliane Gonçalves dos Santos ${ }^{2}$ \\ Maria Cristina Pansera de Araújo $^{3}$
}

\section{Resumo}

\begin{abstract}
${ }^{1}$ Possui graduação em Bacharelado e Licenciatura - Ciências Biológicas pela Pontifícia Universidade Católica do Rio Grande do Sul - Campus Uruguaiana (2007) e mestrado em Biologia - Diversidade e Manejo de Vida Silvestre pela Universidade do Vale do Rio dos Sinos (2010). Professora da Universidade Federal da Fronteira Sul (UFFS) desde 2013 na área de Ensino de Ciências/Biologia. Atualmente professora no campus Cerro Largo/RS. Doutoranda no Programa de Pós-Graduação em Educação nas Ciências da Universidade Regional do Noroeste do Estado do Rio Grande do Sul (UNIJUí).

2 Licenciada em Ciências Biológicas pela Universidade Regional Integrada do Alto Uruguai e das Missões (2002). Especialização em Interdisciplinaridade pela FACIPAL (2003). Mestrado em Ensino Científico e Tecnológico (2011) pela URI. Doutora em Educação nas Ciências (UNIJUÍ). Já atuou na educação básica nas disciplinas de Ciências e Biologia. Tutora EaD do curso de Pedagogia da UFPel. Atualmente professora de Prática de Ensino e Estágio Supervisionado em Ciências e Biologia da Universidade Federal da Fronteira Sul - Campus Cerro Largo, atuando na pesquisa, extensão e docência, principalmente nos seguintes temas: formação de professores, cinema e o ensino de ciências/biologia, educação em saúde.Coordenou o PIBID Ciências Biológicas, coordenadora do Subprojeto Residência Pedagógica Multidisciplinar e membro do grupo de pesquisa GEPECIEM.

3 Possui graduação em Licenciatura em Ciências Biológicas pela Universidade do Vale do Rio dos Sinos (1978), mestrado em Genética e Biologia Molecular pela Universidade Federal do Rio Grande do Sul (1981) e doutorado em Genética e Biologia Molecular pela Universidade Federal do Rio Grande do Sul (1997). Atualmente é professora titular da Universidade Regional do Noroeste do Estado do Rio Grande do Sul, Departamento de Ciências da Vida e no Programa de Pós-Graduação em Educação nas Ciências. Tem experiência na área de pesquisa em educação, biodiversidade, curriculo, ensino de ciências e de biologia, ensino de Genética, pesquisa com ênfase em Interações Insetos Plantas e biologia do desenvolvimento animal e humana. Coordena o Grupo interdepartamental de Pesquisa em Ensino de Ciências-Unijui. Pesquisas em Ciência, Tecnologia, Sociedade e Ambiente.
\end{abstract}

Interfaces da Educ., Paranaíba, v.10, n.28, p.423 à 444, 2019

ISSN 2177-7691

Recebido em março de 2019 e aprovado em setembro de 2019 
Esta investigação teve como objetivo identificar compreensões e transformações necessárias para a formação inicial de professores de ciências pela constituição do terceiro espaço. A pesquisa qualitativa em Educação em Ciências permitiu a análise das narrativas escritas, nos diários de bordo de quatro futuras professoras, no segundo semestre de 2017, que participam do Programa Institucional de Bolsas de Iniciação à Docência (PIBID), subprojeto Ciências Biológicas de uma universidade federal do Rio Grande do Sul. Utilizamos a análise textual discursiva (ATD - MORAES; GALIAZZI, 2013) e as categorias a priori: práticas, profissão, pessoa, partilha e público, propostas por Nóvoa (2009). A análise permite afirmar a importância do PIBID, como terceiro espaço (ZEICHNER, 2010), propulsor da formação e constituição de um bom professor dentro da profissão, nas interações proporcionadas entre Universidade e Escolas de Educação Básica, com o uso do diário de bordo como instrumento de reflexão e tomada de consciência indispensável, neste processo formativo.

Palavras-Chave: Constituição docente. Ensino de Ciências. Narrativas. Diário de bordo.

\section{Abstract}

This research aimed to identify understandings and transformations necessary for the initial formation of science teachers by the constitution of the third space. Qualitative research in Science Education allowed the analysis of written narratives in the logbooks of four future teachers in the second semester of 2017, who participate in the Programa Institucional de Bolsas de Iniciação à Docência (PIBID), Biological Sciences subproject of a federal university of Rio Grande do Sul. We use the discursive textual analysis (ATD - MORAES; GALIAZZI, 2013) and the a priori categories: practices, profession, person, sharing and public, proposed by Nóvoa (2009). The analysis allows to affirm the importance of PIBID, as a third space (ZEICHNER, 2010), propelling the formation and constitution of a good 
teacher within the profession, in the interactions provided between University and Basic Education Schools, using the logbook as instrument of reflection and indispensable awareness, in this formative process.

Key-Words: Teaching Constitution. Science teaching. Narratives. Logbook.

\section{INTRODUÇÃO}

Como nos constituímos bons professores? Como nos trans (formamos) em bons professores? Quais são os elementos necessários para a formação de um bom professor? Não são respostas simples, mas é preciso compreender a importância da reflexão constante, da formação ao longo da vida, da racionalidade prática e da investigação da própria prática. Estes princípios precisam estar presentes, o que nos remete à reflexão de Nóvoa (2009, p. 23) sobre a docência: "parece que todos sabemos, e até concordamos, com o que deve ser o futuro da profissão docente. Mas temos dificuldade em dar passos concretos nesse sentido".

Independente da área, os formadores de professores precisam potencializar a formação próxima do futuro local de atuação, este precisa ser o ponto de partida para a constituição de um bom professor. Este é o primeiro passo concreto: a formação de professores "dentro da profissão", termo designado por Nóvoa (2012). Cabe destacar que não se trata de atribuir a responsabilidade à Escola ou uma simples transferência de local para esta formação, da Instituição de Ensino Superior, mas de um "terceiro espaço", conforme Zeichner (2010).

O terceiro espaço pode ser entendido como ambiente híbrido “[...] nos programas de formação inicial de professores que reúnem professores da Educação Básica e do Ensino Superior, e conhecimento prático profissional e acadêmico em novas formas para aprimorar a aprendizagem dos futuros professores (ZEICHNER, 2010, p. 497)”. Potencializar este espaço híbrido e compartilhado por professores em formação inicial, professores da Educação

Interfaces da Educ., Paranaíba, v.10, n.28, p.423 à 444, 2019 
Básica e do Ensino Superior é um desafio para os programas de formação de professores, por se tratar de uma relação de estreitamento e aproximação entre essas duas instituições de ensino e seus profissionais. Conforme Nóvoa (2012, p. 12) destaca, é a "[...] fusão dos espaços acadêmicos e institucionais das escolas e da formação de professores [...] a criação de uma nova realidade organizacional no interior da qual estejam integrados" os três sujeitos professores. Desde a implementação, o PIBID tem possibilitado uma relação e diálogo entre Universidade e Escola.

Concordamos com Felício (2014), ao considerar o PIBID como o terceiro espaço na formação de professores, pelas seguintes razões:

- distingue-se do estágio curricular obrigatório na consideração do cenário escolar;

- permite a inserção antecipada do licenciando na escola, que se assume como parceira no processo de formação inicial docente, ao acolhê-lo, por intermédio dos supervisores;

- compreende uma configuração que possibilita a participação de professores da universidade (coordenador de área), responsáveis diretos pelos licenciandos bolsistas, e do professor da escola de Educação Básica (supervisor), responsável pelo licenciando, quando ele se encontra na escola desenvolvendo as atividades de iniciação à docência;

- pressupõe um diálogo constante entre licenciando, coordenador de área e supervisor;

- são previstas ações visando iniciar o licenciando na docência tendo por base experiências reais, advindas do contexto escolar;

- assume o movimento de reflexão-ação-reflexão como pressuposto fundamental para o desenvolvimento das atividades;

- propicia a permanência contínua dos licenciandos no cotidiano escolar, por um período de, pelo menos, dois anos (FELÍCIO, 2014, p. 423).

Diante destes aspectos, compreendemos que este é um desafio que precisa ser iniciado pelos professores formadores e apostamos nesta formação construída dentro da profissão num terceiro espaço constituído pelos três sujeitos professores. Assim, por meio do Programa Institucional de Bolsa de Iniciação à Docência (PIBID), financiado pela Coordenação de Aperfeiçoamento de Pessoal de Nivel Superior (CAPES), cuja finalidade é: contribuir para a formação de professores em nivel superior, tendo como objetivo incentivar a formação de docentes para a Educação Básica; elevar a qualidade da formação inicial de professores; inserir os licenciandos no

Interfaces da Educ., Paranaíba, v.10, n.28, p.423 à 444, 2019 
cotidiano e a cultura escolar. A partir desses pressupostos, temos buscado avançar no desafio de formar professores qualificados e comprometidos com a docência, com o ser professor, que superem a lógica da racionalidade técnica do ensino e a visão simplista da docência (CARVALHO; GIL-PÉREZ, 2011).

Neste sentido, encontramos, nos trabalhos de Nóvoa (2009; 2012), o argumento sobre o resgate da profissionalidade por meio da formação de professores dentro do contexto de atuação num movimento de partilha entre futuros professores, professores da Educação Básica e do Ensino Superior. O autor discute esse aspecto, com exemplos de outras profissões.

A colegialidade, a partilha e as culturas colaborativas não se impõem por via administrativa ou por decisão superior. Mas o exemplo de outras profissões, como os médicos, os engenheiros ou os arquitectos, pode inspirar os professores. A forma como construíram parcerias entre o mundo profissional e o mundo universitário, como criaram processos de integração dos mais jovens, como concederam uma grande centralidade aos profissionais mais prestigiados ou como se predispuseram a prestar contas públicas do seu trabalho são exemplos para os quais vale a pena olhar com atenção (NÓVOA, 2012, p. 12).

O autor propõe uma nova compreensão do "bom professor" por meio de cinco disposições para caracterizar o trabalho docente: o conhecimento, a cultura profissional, o tacto pedagógico, o trabalho em equipe e o compromisso social.

Ao sugerir um novo conceito, disposição, pretendo romper com um debate sobre as competências que me parece saturado. Adopto um conceito mais "liquído" e menos "sólido", que pretende olhar preferencialmente para a ligação entre as dimensões pessoais e profissionais na produção identitária dos professores (NÓVOA, 2009, p.29).

Sobre os momentos relacionados às disposições - cultura profissional e tacto pedagógico - Nóvoa (2009) identifica cinco posições necessárias no processo formativo: as práticas, a profissão, a pessoa, a partilha e o público.

Este artigo teve como objetivo refletir sobre o processo formativo de quatro futuras professoras, participantes do subprojeto PIBID Ciências Biológicas, da Universidade Federal da Fronteira Sul (UFFS), Campus Cerro 
Largo \RS. No intuito de identificar as transformações e compreensões sobre a formação e a constituição docente partir da formação compartilhada, processo conhecido como triade de interação (ZANON, 2003). Entendemos que o PIBID, como terceiro espaço, potencializa uma formação construída dentro da profissão. Desta maneira, optamos pela análise com base no aporte teórico das dimensões elencadas por Nóvoa (2009) como necessárias para a formação e constituição de um bom professor: práticas, profissão, pessoa, partilha e público por meio da análise dos diários de bordo de quatro licenciandas.

\section{Procedimentos metodológicos}

\section{$O$ contexto da investigação}

A investigação teve como foco o subprojeto PIBID Ciências Biológicas da Universidade Federal da Fronteira Sul (UFFS) - Campus Cerro Largo/RS, constituído por 33 bolsistas: 26 licenciandos do Curso de Ciências Biológicas - Licenciatura, duas coordenadoras de área (formadoras) e cinco supervisoras (professoras da Educação Básica). A UFFS tem como característica ser multicampi e localiza-se nos três estados da Região Sul do Brasil: Paraná (PR), Santa Catarina (SC) e Rio Grande do Sul (RS). O Campus Cerro Largo pertence à Região das Missões, no Noroeste do Estado do RS. Em nosso Campus temos quatro subprojetos do PIBID na área de Ciências da Natureza: Interdisciplinar, Física, Química e Ciências Biológicas.

Utilizamos o diário de bordo como instrumento formativo, no qual os sujeitos por meio de narrativas refletem e investigam suas práticas e concepções, favorecendo o processo de constituição docente. Portanto, o diário de bordo tem um papel fundamental, em nosso terceiro espaço, como instrumento para organizar a reflexão sobre a prática docente ao possibilitar a tomada de consciência do processo e dos próprios modelos de referência do professor, tanto na formação inicial quanto ao longo da profissão; ao

Interfaces da Educ., Paranaíba, v.10, n.28, p.423 à 444, 2019 
estabelecer conexões entre os conhecimentos práticos e disciplinares propicia o desenvolvimento de decisões fundamentadas (PORLÁN; MARTÍN, 2000). Os diários de bordo constituem importantes instrumentos de análise dos conhecimentos de professor expressos pelos sujeitos envolvidos nos processos de ensino e aprendizagem em Ciências.

$\mathrm{Na}$ integração entre Escola e Universidade, buscamos por meio do PIBID Ciências Biológicas, a inserção dos licenciandos, bolsistas, no contexto escolar desde o seu início no programa. Uma das ações do nosso subprojeto, executada pelos futuros professores, é o acompanhamento das atividades das professoras supervisoras das disciplinas de Ciências e $\backslash$ ou Biologia em sala de aula, auxiliando-as sempre que possivel na confecção de materiais didáticos, desenvolvimento de atividades experimentais, além do planejamento conjunto de uma aula, ministrada pelo(s) bolsista(s) com a supervisão e o acompanhamento desta professora supervisora. Cada licenciando, em seus respectivos diários de bordo, faz o registro de todas as atividades desenvolvidas com o intuito de refletir sobre o processo formativo propiciado neste terceiro espaço.

As relações estabelecidas, por meio do PIBID com a Escola, visam a formação dentro da profissão e caracterizam-se como uma via de mão dupla, por possibilitar diálogos entre diferentes conhecimentos, experiências e saberes dos sujeitos envolvidos no processo. Os momentos são importantes para a constituição do futuro professor e contribuem para a aproximação da Universidade com as Escolas do municipio de Cerro Largo.

\section{A análise dos diários de bordo}

É uma pesquisa qualitativa em Educação nas Ciências, trata-se de um recorte temporal das narrativas de quatro professoras em formação inicial que participam do subprojeto PIBID Ciências Biológicas da UFFS - Campus Cerro Largo/RS, do segundo semestre de 2017. O instrumento de obtenção de dados constituiu-se das narrativas dos diários de bordo das quatro 
bolsistas, que ingressaram no programa praticamente juntas. Todas estão no programa há pelo menos um ano, com o acompanhamento de supervisoras distintas, e nenhuma cursou os estágios de regência em Ciências e/ou Biologia.

Utilizamos para análise dos dados, a Análise Textual Discursiva (ATD), que se constitui em três etapas: a desconstrução (unidades de análise); a reordenação (categorias); e a comunicação (metatexto) (MORAES, 2003). As categorias foram anteriores à análise e propostas por Nóvoa (2009): práticas (P1), profissão (P2), pessoa (P3), partilha (P4) e público (P5). Elas foram selecionadas, pois representam a necessidade de uma formação de professores dentro da profissão (Quadro 1), em que os são basilares para a constituição de bons professores.

Quadro 1: Definição das categorias escolhidas a priori

\begin{tabular}{|c|c|c|c|c|}
\hline P1 - Práticas & P2 - Profissão & P3 - Pessoa & P4 - Partilha & P5 - Público \\
\hline \multicolumn{5}{|c|}{ A formação de professores precisa: } \\
\hline $\begin{array}{l}\text { assumir uma } \\
\text { forte } \\
\text { componente } \\
\text { práxica, } \\
\text { centrada na } \\
\text { aprendizagem } \\
\text { dos alunos e } \\
\text { no estudo de } \\
\text { casos } \\
\text { concretos, } \\
\text { tendo como } \\
\text { referência o } \\
\text { trabalho } \\
\text { escolar. }\end{array}$ & $\begin{array}{l}\text { passar para } \\
\text { "dentro" da } \\
\text { profissão, isto é, } \\
\text { deve basear-se na } \\
\text { aquisição de uma } \\
\text { cultura } \\
\text { profissional, } \\
\text { concedendo aos } \\
\text { professores mais } \\
\text { experientes um } \\
\text { papel central na } \\
\text { formação dos } \\
\text { mais jovens. }\end{array}$ & $\begin{array}{l}\text { dedicar uma } \\
\text { atenção } \\
\text { especial às } \\
\text { dimensões } \\
\text { pessoais da } \\
\text { profissão } \\
\text { docente, } \\
\text { trabalhando } \\
\text { essa } \\
\text { capacidade de } \\
\text { relação e de } \\
\text { comunicação } \\
\text { que define o } \\
\text { tacto } \\
\text { pedagógico. }\end{array}$ & $\begin{array}{lr}\text { valorizar } & \text { o } \\
\text { trabalho } & \text { em } \\
\text { equipe e } & \text { o } \\
\text { exercício } & \\
\text { coletivo } & \text { da } \\
\text { profissão, } \\
\text { reforçando a } \\
\text { importância } \\
\text { dos projetos } \\
\text { educativos da } \\
\text { escola. }\end{array}$ & $\begin{array}{l}\text { estar marcada } \\
\text { por um principio } \\
\text { de } \\
\text { responsabilidade } \\
\text { social, } \\
\text { favorecendo a } \\
\text { comunicação } \\
\text { pública e a } \\
\text { participação } \\
\text { profissional no } \\
\text { espaço público da } \\
\text { educação. }\end{array}$ \\
\hline
\end{tabular}

Fonte: Adaptado de Nóvoa (2009).

Seguimos os preceitos éticos da pesquisa com seres humanos, pois o projeto foi submetido e aprovado no comitê de ética na pesquisa. As participantes do grupo foram convidadas a participar da pesquisa, e, as que concordaram, assinaram o termo de consentimento livre e esclarecido (TCLE). Para garantir o sigilo, anonimato e autoria das falas dos sujeitos, utilizamos nomes fictícios. As bolsistas-licenciandas foram designadas pelos nomes: Graziela, Andrea, Ana Maria e Saionara, e à medida que as análises 
das narrativas registradas nos diários de bordo delas foram realizadas, outros nomes fictícios foram utilizados para nomear colegas e supervisoras citadas.

\title{
Análise e discussão
}

\section{Reflexões das futuras professoras de ciências sobre suas narrativas}

A partir da análise encontramos nos diários de bordo das licenciandas marcas de uma formação de professores dentro da profissão, em que o terceiro espaço do processo foi o subprojeto PIBID Ciências Biológicas. As narrativas permitiram o resgate da memória da trajetória das quatro licenciandas; deste modo, podemos investigar a memória do processo de formação de professores e identificar as vivências que provocaram a constituição das futuras professoras (WYZYKOWSKI; FRISON, 2015).

\section{Práticas}

A práxis tem papel central tanto na formação como ao longo da profissão. Partindo desta compreensão, Carr e Kemmis (1988, p. 61) relacionam a práxis ao saber do professor e a importância da reflexão crítica na indissociação entre teoria e prática:

\begin{abstract}
o saber do professor proporciona um ponto de partida para a reflexão crítica. Simplesmente, não pode dar-se por pronto ou sistematizado a teoria, nem tomar-se definitivo na prática. [...] O saber acerca da educação há de mudar de acordo com as circunstâncias históricas, os contextos sociais e o diferente entendimento dos protagonistas frente ao que acontece durante o encontro educativo (CARR; KEMMIS, 1988, p. 61 [tradução nossa]).
\end{abstract}

Neste sentido, a formação de professores precisa ter como referência situações concretas "práticas" que, na medida em que são resolvidas, movimentarão os conhecimentos teóricos (NÓVOA, 2009). Podemos observar este movimento no excerto da narrativa de Graziela sobre o processo vivenciado, ao desenvolver uma atividade com os alunos do $7^{\mathrm{a}}$ ano, a construção de um meio de cultura para a formação de bactérias. 
Ao corrigir as questões tomei a decisão de não dar certo ou errado e sim fui riscando palavras equivocadas, e colocando outras pedindo para complementarem enquanto fazia a correção lembrei das nossas leituras de Pórlan e Martín, que devemos fazer planejamento e roteiros, mas não devemos ficar presos a eles, senti que preciso retomar algumas coisas com eles, mesmo que já tenha planejado o que fazer na próxima aula (GRAZIELA, 2017 [grifos nossos]).

A partir dos referenciais estudados e discutidos, nos encontros do grupo, Graziela identificou, após a escrita em seu diário de bordo, a necessidade de repensar as aulas e focar em outros aspectos dos processos de ensino e aprendizagem, a futura professora refletiu sobre a sua própria prática transformando as ações em práxis.

Concordamos com Nóvoa (2009), de que a superação da dicotomia entre teoria e prática está atrelada à compreensão da importância dos conhecimentos refletidos e constituídos no processo histórico. Estes aspectos são identificados por Andrea ao refletir sobre o processo de planejamento e a proposta de trabalhar com as tecnologias da informação (TIC) e comunicação com a turma do $9^{\circ}$ ano:

com a criação do grupo no face, Sexualidade, o qual estão inseridos todos os alunos, vamos poder interagir, refletir diante das ideias propostas pelos alunos, isso faz com que nos aproximemos mais da realidade atual onde o mundo respira tecnologia $[. .$.$] internet \mathrm{e}$ suas web's. Acabo por acreditar que o principal objetivo desse planejamento é aproximar nós futuros professores dos alunos fazendo a nossa própria 'inserção' no 'mundinho' deles, até porquê um dia já estivemos no lugar deles e foram poucas às vezes que estivemos aptos a uma atividade diferente que nos instigasse a curiosidade. Portanto, faremos o contrário instigando assim a curiosidade e interesse desses alunos (ANDREA, 2017 [grifos nossos]).

Nóvoa (2009) alerta que não se trata de uma simples aplicação prática de qualquer teoria. É fundamental a constante reflexão do conhecimento pertinente e o que demanda um esforço constante de reeelaboração deste conhecimento. Neste sentido, Ana Maria relatou preocupação, ao refletir a respeito de uma aula sobre a temática alimentação saudável:

[...]. Ficamos desconcertados quando percebemos que a maioria dos alunos não entendia os termos que falávamos tratavam-se de termos simples como hemáceas, catarata, glóbulos brancos e insulina, mas a resposta geralmente era o silêncio quando questionados sobre, então mudamos um pouco o foco da aula e comentamos tais termos. No geral, a turma se mostrou bem 
participativa, respondendo e interagindo o que me espantou, pois já estava habituada às reclamações da EJA. Para finalizar distribuímos um questionário para que eles refletissem sobre seus hábitos alimentares, então montamos um cartaz com a pirâmide alimentar. Acredito que poderiamos ter contextualizado mais o conteúdo e talvez até investir mais no entendimento dos termos científicos, acho que mais adiante podemos montar um glossário com eles [...] (ANA MARIA, 2017 [grifos nossos]).

A interação com a professora mais experiente possibilitou que Ana Maria e seus colegas, identificassem a situação e tomassem uma decisão sobre o andamento da aula perante as dificuldades de entendimento dos alunos. Precisamos potencializar uma formação, nesta perspectiva, considerando a nossa responsabilidade e a reflexão sobre as mudanças em nossas rotinas e a inovação (NÓVOA, 2009), visando uma formação qualificada, um profissional pesquisador da sua prática e conectado com os desafios da docência e do ensino.

Sobre este aspecto, Saionara abordou em seu diário de bordo a responsabilidade da profissão:

para conseguir realizar aulas legais eu precisarei ser uma
professora pesquisadora que vai atrás das informações e
atualizações de conteúdos e novas metodologias de trabalho
tentando adequar sempre, o conteúdo com a realidade escolar,
partindo dos conhecimentos prévios dos alunos, investindo em aulas
práticas [...] (SAIONARA, 2017 [grifos nossos]) .

As narrativas das futuras professoras trazem reflexões sobre a importância da formação inicial vinculada ao contexto concreto da futura profissão refletida e alicerçada nos referenciais teóricos da área, apoiados por professores experientes da Escola e da Universidade. Este “[...] movimento dialético de reflexão-ação-reflexão sobre a prática pedagógica, no contexto real da docência, proporcionada pelo PIBID, introduz o licenciando, desde o início de sua formação, no universo do exercício profissional, possibilitando que ele problematize a prática [...] (FELÍCIO, 2014, p. 426)". São elementos importantes para a compreensão da carreira: perceber a prática educativa de maneira investigativa, reflexiva e crítica, bem como se 
faz necessário o professor saber relacionar com mobilidade de pensamento entre teoria e prática, conforme destacam Wyzykowski e Frison (2015).

É preciso levar o professor em formação inicial a compreender a carreira para, então, poder melhor formá-lo para atuar na profissão, pois a prática educativa não é uma tarefa simples e necessita de uma condução de modo investigativo, reflexivo e critico. Para tanto, se faz necessário formar profissionais que saibam relacionar uma mobilidade de pensamento entre a teoria e a prática, com uma clareza crítica quanto à fonte que referencia o trabalho em sala de aula (WYZYKOWSKI; FRISON, 2015, p. 47).

Este processo formativo contribui para a constituição de profissionais que refletem sobre suas práticas, investiguem situações e resolvem problemáticas relacionadas aos processos de ensino e aprendizagem em sala de aula. A reflexão sobre a prática possibilita a transformação e a inovação no contexto escolar.

\section{Profissão}

É coerente que a formação de professores não pode acontecer de maneira desarticulada ao seu futuro local de trabalho e precisa, além disso, contar com os profissionais experientes que atuam neste espaço. Contraditoriamente, uma das dificuldades de muitos programas de formação é a ausência dos professores da Escola e a falta desta cultura profissional (NÓVOA, 2009). O autor alerta sobre a urgência de "[...] devolver a formação de professores aos professores (NÓVOA, 2009, p.36)" e sobre o importante papel do professor experiente na formação dos futuros professores.

$\mathrm{Na}$ narrativa de Graziela, percebemos a importância da formação dentro da profissão para a futura professora, ao relatar o seu sentimento ao estar na Escola:

dia de escola me traz tranquilidade, os ombros pesam um pouco menos lá dentro, pois estar dentro de uma escola é como estar com o pé no futuro, apesar dos inúmeros desafios que ouço, vejo e leio, sinto que o conjunto que a universidade é, passa a sensação de que é mais 'pesado' que a futura profissão anunciada (GRAZIELA, 2017 [grifos nossos]).

Interfaces da Educ., Paranaíba, v.10, n.28, p.423 à 444, 2019 
Saionara também registrou a importância formativa de estar em contato com o futuro local de trabalho: apoiada pela professora mais experiente, após desenvolver de uma aula, expressou seu sentimento em relação aos estágios em regência e a futura profissão.

Este resultado me motiva a continuar nesta caminhada, mesmo sabendo do esforço que vem pela frente. Acredito que avaliando minha aula eu consiga refletir sobre o que eu preciso continuar fazendo e o que devo melhorar. [...]. Espero que estas práticas reflitam nos momentos de estágio e me amadureçam cada vez mais para poder ser uma boa profissional um dia (SAIONARA, 2017 [grifos nossos]) .

As narrativas das licenciandas evidenciam a importância da formação de professores neste terceiro espaço, o PIBID, que se constitui como uma comunidade de formadores de professores (NÓVOA, 2009) em proximidade com o ambiente escolar, com os desafios da profissão, com o acompanhamento de professores experientes da Educação Básica e da Universidade. Conforme destacou Andrea os desafios enfrentados na Escola e experienciados na formação inicial por estar no PIBID:

\footnotetext{
entrar em sala de aula, a cada dia que passa é um desafio diferente, mas o PIBID está me fazendo ter uma base de como será daqui para frente. Está me preparando para as frustrações e alegrias que virão. Esse processo, tenho certeza [...] vai me afetar positivamente, vou obter um crescimento, possibilitará abertura da minha mente, o estouro da bolha. Todo conhecimento será agregado na minha bagagem". Além dos desafios, Ana Maria enfatiza as aprendizagens e seu sentimento de confiança em relação à profissão: "[...] aprendi muito desde que cheguei no programa [PIBID], e cada vez me sinto mais confiante para enfrentar os estágios e minha futura profissão (ANDREA, 2017 [grifos nossos]).
}

Percebemos nas narrativas das duas licenciandas, Saionara e Andrea, que, a partir do confronto por meio de situações problemáticas educativas vivenciadas, a inserção no PIBID, o conhecimento da realidade do ambiente escolar, a interação com os professores, o desenvolvimento de diferentes estratégias de ensino e o acompanhamento das turmas lhes conferiu segurança e o sentimento de responsabilidade pela própria formação. Concordamos com Felício (2014) sobre os significados do PIBID na formação dos licenciandos:

Interfaces da Educ., Paranaỉba, v.10, n.28, p.423 à 444, 2019 
quanto aos significados atribuídos pelos licenciandos às experiências do PIBID, destacamos, em primeiro lugar, o reconhecimento do PIBID como vivência que tem contribuído para o processo de construção da identidade do professor, uma vez que tal experiência vem sendo construída na escola - espaço de atuação profissional docente - em contato com professores que vivenciam a profissão e que contribuem, fundamentalmente, para a formação de novos professores. [...] Esse significado reforça a necessidade do estreitamento de relações entre universidade e escola no processo de formação inicial de professores e na construção desse terceiro espaço' [...] (FELÍCIO, 2014, p. 425).

Cabe destacar que o período de transição de aluno para professor, vivenciado pelas bolsistas, é essencial para "[...] consolidar as bases de uma formação que tenha como referência lógica de acompanhamento, de formação-em-situação, de análise da prática e de integração na cultura profissional docente (NÓVOA, 2009, p. 38)", sendo fundamental, para tanto, o terceiro espaço na formação de professores, pois as vivências no ambiente escolar, articuladas às discussões entre pares proporcionam um percurso formativo de conhecimento e compreensão da futura profissão.

\title{
Pessoa
}

Nóvoa (2009) propõe a construção de uma teoria da pessoalidade no interior de uma teoria da profissionalidade na formação de professores. $O$ autor argumenta não ser possivel a distinção entre as dimensões pessoal e profissional. Concordamos com o autor que é inerente o autoconhecimento e a autoanálise no conhecimento profissional.

\begin{abstract}
Refiro-me à necessidade de elaborar um conhecimento pessoal (um auto-conhecimento) no interior do conhecimento profissional e de captar (de capturar) o sentido de uma profissão que não cabe apenas numa matriz técnica ou científica. Toca-se aqui em qualquer coisa de indefinivel, mas que está no cerne da identidade profissional docente (NÓVOA, 2009, p. 39).
\end{abstract}

Houve indícios na narrativa de Saionara da elaboração do seu conhecimento pessoal ao escrever em seu diário de bordo uma autorreflexão e uma autoanálise sobre características e aspectos, os quais considerou importantes serem superados para o desenvolvimento da futura profissão, bem como o papel do PIBID para o desenvolvimento pessoal e profissional e como este terceiro espaço possibilita sentir-se professora:

Interfaces da Educ., Paranaíba, v.10, n.28, p.423 à 444, 2019 
[...] durante a graduação sempre convivi com esta realidade de me fechar, ter vergonha de falar em público, expressar uma ideia. Acredito que tenho mais facilidade de me expressar através da escrita. E estou ciente de que tenho um grande desafio a ser superado, porque na minha atuação profissional, interagir com o público é umas das características-chave de um professor. Acredito que com o tempo e as experiências que sou submetida através do programa PIBID, eu possa superar esta etapa (SAIONARA, 2017 [grifos nossos]).

Graziela escreveu, em seu diário de bordo, seus sentimentos em relação à turma que acompanharia a professora supervisora na Escola ao longo do semestre, devido a um episódio anterior:

neste dia a prof. Maria nos disse quais turmas vamos trabalhar mais especificamente, amoleceu minhas pernas quando ela me disse que vou ficar com o $7^{\circ}$ ano, pois essa turma no semestre passado quebrou uma janela [...] e uma menina derrubou propositalmente duas vezes a cadeira no chão e na terceira vez que ia fazer isso tive que tomá-la o que me exigiu um comportamento tão agressivo quanto o dela e me fez chorar quando cheguei em casa, porém a prof. me falou que estão mais fáceis agora [...] acho que é um desafio para mim e é bom que venha neste tempo que sou pibidiana, pois não me sinto sozinha, estou acompanhada de supervisora e ótimos colegas, de momento me concede mais autoconfiança (GRAZIELA, 2017 [grifos nossos]).

Graziela rememorou, na narrativa, o quanto se sentiu diante da situação vivenciada e se posicionar, tomar uma atitude como professora que ela no momento considerou desagradável. A escrita sobre o episódio também impulsionou Graziela a se analisar e querer modificá-lo, desafiando-se e sentindo-se confiante por poder contar com a professora supervisora e com seus colegas do programa. Quando a bolsista afirma que "é bom" situações como esta acontecerem enquanto está no PIBID, vai ao encontro do que cita Imbernón (2009, p. 62) que "aprender num ambiente de colaboração, de diálogo profissional e interação social: compartilhar problemas, fracassos e êxitos", possibilita que se crie um espaço de escuta, comunicação e de aprendizado do ser professor.

Andrea e Ana Maria relataram o sentimento de nervosismo ao desenvolver uma aula principalmente em relação ao envolvimento dos alunos. Andrea escreveu sobre o início de uma aula: "dia de iniciar a 
aplicação do planejamento sobre sexualidade no $8^{\circ}$ ano. É a $\mathbf{1}^{\mathbf{a}}$ vez que trabalho com essa turma, confesso que estava nervosa, mas que ao desenvolver a aula, os alunos interagiram, perdi o receio". Enquanto Ana Maria escreveu que todos os futuros professores sentem-se nervosos ao conhecer uma nova turma ou nova Escola e que isso também deve acontecer para os alunos que não conhecem o novo professor:

[...] até mesmo os estagiários mais experientes falam que o nervosismo é algo comum, pois os alunos sempre são diferentes, sempre muda e você sempre deve estar preparado para essa mudança. Quando chegamos na escola também é normal que os alunos fiquem desconfortáveis e acanhados, então é necessário que o professor busque diferentes meios de integrar a turma, fazendo com que estes se sintam confortáveis para questionarem e responderem (ANA MARIA, 2017 [grifos nossos]).

Neste processo formativo, a escrita e as narrativas têm um papel fundamental, ao potencializarem a autorreflexão e a autoanálise das futuras professoras sobre suas histórias de vida, pois “[...] cada professor constrói uma trajetória singular no processo de desenvolvimento de seu aprendizado profissional (PERRELLI et al., 2013, p. 11)". Os formadores precisam incentivar os futuros professores na construção de narrativas, auxiliando-os a refletir sobre os processos vivenciados e apresentar caminhos para o seu desenvolvimento pessoal e profissional.

\section{Partilha}

Concordamos com Nóvoa (2009, p. 41) sobre a docência como coletivo:

[...] ideia da escola como o lugar da formação dos professores, como o espaço da análise partilhada das práticas, enquanto rotina sistemática de acompanhamento, de supervisão e de reflexão sobre o trabalho docente. O objetivo é transformar a experiência coletiva em conhecimento profissional e ligar a formação de professores ao desenvolvimento de projetos educativos nas escolas (NÓVOA, 2009, p. 41).

É imprescindivel percebermos a docência como coletivo não apenas em relação ao conhecimento, mas também à ética, conforme o autor destaca. Há necessidade da partilha de situações, dos problemas concretos no ambiente escolar dos quais não há respostas prontas que exigem uma ética 
profissional construída no diálogo com os colegas, potencializando o sentimento de pertencimento e reforçando a identidade docente.

Não há respostas feitas para o conjunto de dilemas que os professores são chamados a resolver numa escola marcada pela diferença cultural e pelo conflito de valores. Por isso, é tão importante assumir uma ética profissional que se constrói no diálogo com os outros colegas (NÓVOA, 2009, p. 41).

As futuras professoras destacaram nas narrativas a importância da partilha das práticas, do acompanhamento, da supervisão para a reflexão sobre o trabalho docente, do sentimento de pertencimento e da identidade docente. Graziela destacou como se sentiu ao desenvolver uma atividade em sala de aula com a presença de seus colegas do PIBID e a professora supervisora:

durante a prática percebi a importância que teve a presença da minha colega e da professora, pois em determinadas ocasiões as tarefas tinham que ser feitas rapidamente e sozinha teria sido mais lento, além do mais contei com a experiência da prof. Maria que ia remendando alguns furos meus, por isso não me sinto segura para entrar em uma sala sozinha, por isso estou no PIBID, apesar de já ter percebido uma melhora desde a última prática, dessa vez falei mais devagar e tomei mais cuidado com as questões (GRAZIELA, 2017 [grifos nossos]).

Andrea escreveu sobre a importância de acompanhar uma aula que foi desenvolvida por outros colegas do PIBID para conhecer a turma e se sentir mais acolhida na Escola:

[...] eu e Larissa observamos a aula dos colegas José e Ricardo sobre o ar no $5^{\circ}$ ano, observamos que a turma era bastante interativa e inclusive portava um aluno especial muito bem recebido pelos colegas. [colegas] deram uma boa aula, conseguiram suprir todas as dúvidas dos alunos [...]. Achei importante a observação da aula dos colegas porque assim aprendi e relembrei muitos conteúdos, pude conhecer ainda mais o âmbito escolar e os alunos [...] e a partir dai me senti mais à vontade [na escola] (ANDREA, 2017 [grifos nossos]).

Ana Maria também acompanhou o desenvolvimento de uma aula e destacou outros aspectos importantes na rotina do trabalho docente:

fui acompanhar a aula dos colegas Felipe e Luís [...]. Achei uma experiência interessante, pois mesmo que os alunos sejam bem barulhentos, querendo falar e participar ao mesmo tempo, mas este barulho, [...], é realmente de interação, eles estão falando 
contigo. [...] Percebi também que por eles serem pequenos temos que ter o dobro de paciência [...] (ANA MARIA, 2017 [grifos nossos]).

Saionara escreveu em seu diário sobre uma manhã na Escola, observações ao acompanhar a aula desenvolvida pela supervisora e relatou o trabalho coletivo entre ela e a professora:

neste dia realizei um acompanhamento da aula de ciências do $7^{\circ}$ ano [...]. Percebi que as questões eram elaboradas pela professora e eram bem fáceis de serem interpretadas com uma linguagem bem simples o que eu considero bem importante para a compreensão dos alunos. No restante da manhã a professora propôs que eu avaliasse os conteúdos seguintes a serem trabalhados e pensasse em alguma atividade que poderia trabalhar com a turma ( $7^{\circ}$ ano) durante o semestre. [...] Por fim, ajudei a professora a escolher e baixar alguns videos sobre nematelmintos (SAIONARA, 2017 [grifos nossos]).

Conforme Perrelli et al. (2013), as experiências iniciais marcam profundamente o professor, especificamente os licenciandos precisam sentirse acolhidos.

\begin{abstract}
Nessa condição, os iniciantes sentem a necessidade de ser acolhidos e amparados. Considerando que as experiências de início da carreira podem marcar profundamente o professor, a forma como se dá o acolhimento do professor iniciante pode promover a confirmação, permanência e avanço no desenvolvimento da sua carreira escolhida provisoriamente (caso a escola o apoie, oriente, incentive), ou pode resultar em desistência ou retrocesso quando, ao contrário, a escola o ignora, o deixa sozinho ou faz exigências que ainda não se sente capaz cumprir (PERRELLI et al., 2013, p. 10).
\end{abstract}

As narrativas das futuras professoras apontaram a troca de experiências, o compartilhamento dos momentos vivenciados em contexto concreto das Escolas e o sentimento de pertencimento como importantes não apenas para a formação inicial, mas ao de todo o desenvolvimento profissional. Acordamos com Nóvoa (2009) que estas experiências potencializam a reflexão coletiva sobre mudanças em nossas rotinas profissionais impulsionam a transformação de nossas práticas e a melhoria dos processos de ensino e aprendizagem.

\title{
Público
}

Reintroduzir esta dimensão é um dos grandes desafios para os programas de formação de professores, pois necessita de uma grande 
transformação para ser efetivada: “a concretização desta mudança exige uma grande capacidade de comunicação dos professores e um reforço da sua presença pública (NÓVOA, 2009, p. 43)”. Conforme Nóvoa (2009) é necessário firmar um novo contrato entre os professores e a sociedade para termos um novo espaço público da educação.

Ao analisarmos os diários de bordo das futuras professoras, identificamos o princípio de responsabilidade social nas narrativas. Graziela escreveu sobre o papel do professor para o desenvolvimento de alunos reflexivos e o papel do PIBID neste processo.

\footnotetext{
Desenvolver alunos reflexivos é mais complicado do que parece, na universidade, somente o curso não dá conta de formar professores que entendam dos processos que de conta de um aluno humanizado e reflexivo, pois no cotidiano das faculdades a preocupação é com os conteúdos específicos, por isso o PIBID nos insere nas escolas para que vivenciamos os alunos desenvolvendo suas capacidades, o momento em que estamos no PIBID estamos em um espaço que não é nem escola, nem universidade, é um momento de construir conhecimento a partir do outro (GRAZIELA, 2017 [grifos nossos]).
}

Enquanto Ana Maria enfatizou o princípio da responsabilidade social relacionado à capacidade de decisão sobre os assuntos educativos (NÓVOA, 2009).

[...] ser professor não é uma tarefa fácil, é preciso saber e sentir, o conteúdo é importante sim, mas qual? Temos que ter sensibilidade para reconhecer algo necessário de ser trabalhado, naquele momento e com aquelas pessoas. Sim, pessoas [...] pensantes e com ambições que devem ser levadas em consideração (ANA MARIA, 2017 [grifos nossos]).

Nas respectivas narrativas Graziela e Ana Maria trazem indicios de um aspecto fundamental para a construção do novo espaço público da educação “[...] a capacidade de recontextualizar a escola no seu lugar próprio, valorizando aquilo que é especificamente escolar" (NÓVOA, 2009, p.43). A recontextualização precisa ser exposta ao público, presente nos debates públicos, apresentada para a sociedade, precisa ir 'para fora da escola' (NÓVOA, 2009, p.43). Para o autor, esta exposição pública da profissão é o aspecto central para a mudança da imagem do professor, pois "nas 
sociedades contemporâneas, o prestígio de uma profissão mede-se, em grande parte, pela sua visibilidade social" (NÓVOA, 2009, p.44).

Neste sentido, Andrea refletiu sobre a imagem do professor, a falta de reconhecimento e a necessária valorização da profissão:

[...] a imagem do professor [...] é bastante perceptivel a falta de reconhecimento desse ser tão importante para a sociedade. Pensando nisso, levantei algumas hipóteses sobre porquê não falar do ser professor em sala de aula, da importância de valorizá-lo e acima de tudo respeitá-lo para desmistificar essa ideia de que professores são pessoas de outro mundo, quando na verdade são pessoas como qualquer outras e assim como essas [...] merecem respeito e principalmente valorização pela profissão que escolheram para o bem de uma sociedade (ANDREA, 2017 [grifos nossos]).

Assim como Saionara refletiu sobre a complexidade da profissão, apenas percebida quando vivenciada:

[...] o professor está em constante atividade, no entanto, ele precisa ser mais valorizado pensando na situação em que o país se encontra. $\mathrm{O}$ que quero dizer, é que só vivenciando o cotidiano de um profissional da área educacional é que nos damos conta da responsabilidade que ele tem (SAIONARA, 2017 [grifos nossos]).

Esta reflexão novamente reafirma a defesa de Nóvoa (2009) de que precisamos, como professoras formadoras, contribuir para a tomada de consciência dos professores em formação para a necessidade de participação profissional no espaço público da educação, da responsabilidade social para fora da escola ao nos comunicarmos com o público para reconstruirmos a imagem da profissão.

\section{Considerações finais}

As licenciandas desenvolveram princípios importantes para a constituição do professor, após a análise das narrativas podemos afirmar que a formação inicial dentro da profissão potencializa processos reflexivos. Estes foram possíveis devido à constituição da comunidade de professores por meio do PIBID e do uso o diário de bordo que desencadearam princípios fundamentais de: práticas, profissão, pessoa, partilha e público na formação e na constituição de bons professores.

Interfaces da Educ., Paranaíba, v.10, n.28, p.423 à 444, 2019 
Estes principios precisam fazer parte dos programas de formação de professores para que possamos dar os "passos concretos" para o futuro da profissão. Neste contexto, para avançarmos, destacamos a importância do PIBID como terceiro espaço nas relações e interações entre Universidade e Educação Básica, por permitir aos professores em formação conhecimento do contexto escolar por meio da tríade de interação, da articulação e da aproximação dialógica entre estas duas instituições, possibilitando a formação de professores “dentro" da profissão.

\section{Referências}

CARR, W.; KEMMIS, S. Teoria crítica de la enseñanza: la investigación-acción en la formación del profesorado. Barcelona: Ediciones Martinez Roca, 1988. $245 \mathrm{p}$.

CARVAlHO, A. M. P.; GIL-PÉREZ, D. Formação de professores de Ciências: tendências e inovações. 10. ed. São Paulo: Cortez, 2011. 128p.

FELÍCIO, H. M. S. O PIBID como "terceiro espaço" de formação inicial de professores. Revista Diálogo Educacional, Curitiba, v. 14, n. 42, p. 415-434, 2014. Disponível em:

<http://www2.pucpr.br/reol/pb/index.php/dialogo?dd99=issue\&dd0=475>. Acesso em: 20 fev. 2018.

IMBERNÓN, F. Formação permanente do professorado: novas tendências. São Paulo: Cortez, 2009. 118p.

WYZYKOWSKI, T.; FRISON, M. D. O trabalho pedagógico e sua relação com a constituição da memória: implicações no ser e no constituir-se professor. Interfaces da Educação, Paranaíba, v.6, n.18, p.44-66, 2015. Disponível em: <https://periodicosonline.uems.br/index.php/interfaces/article/view/766/ 906>. Acesso em: 21 fev. 2018.

MORAES, R. Uma tempestade de luz: a compreensão possibilitada pela análise textual discursiva. Ciência \& Educação, Bauru, v. 9, n. 2, p.191-211, 
2003. Disponível em: <http://www.scielo.br/pdf/ciedu/v9n2/04.pdf>. Acesso em: 29 dez. 2015.

NÓVOA, A. Professores: imagens do futuro presente. Lisboa: Educa, 2009. 95 p. Disponivel em:

<www.etepb.com.br/arq_news/2012texto_professores_imagens_do_futuro_pr esente.pdf>. Acesso em: 30 jan. 2015. - Pensar alunos, professores, escolas, politicas. Revista Educação, Cultura e Sociedade, Sinop, v. 2, n.2, p. 7-17, 2012. Disponível em:

$<$ http://sinop.unemat.br/projetos/revista/index.php/educacao/article/view / 1004>. Acesso em: 10 jan. 2018.

PERRELLI, M. A. de S. et al. Narrativas do início da docência: uma investigação-formação com alunas concluintes de um curso de pedagogia. Interfaces da Educação, Paranaíba, v.4, n.10, p.35-46, 2013. Disponível em: $<$ https://periodicosonline.uems.br/index.php/interfaces/article/view/544/ 509> Acesso em: 21 fev. 2018.

ZANON, L. B. Interações de licenciandos, formadores e professores na elaboração conceitual de prática: módulos triádicos na licenciatura de Química. 2003. 294 f. Tese (Doutorado) - Curso de Pós-graduação em Educação, Universidade Metodista de Piracicaba, Piracicaba, 2003.

ZEICHNER, K. Repensando as conexões entre a formação na universidade e as experiências de campo na formação de professores em faculdades e universidades. Revista Educação, Santa Maria, v. 35, n. 3, p. 479-504, 2010. Disponivel em:

<https://periodicos.ufsm.br/reveducacao/article/view/2357> Acesso em: 10 jan. 2018. 